\title{
Clinical Observation on Acupoint Catgut Embedding Combined With Electroacupuncture in the Treatment of Obese Patients with Nonalcoholic Fatty Liver Disease
}

\author{
ZHEN HUANG*, SHUANG LIN SONG AND DI ZHANG ${ }^{1}$ \\ Department of Acupuncture and massage, ${ }^{1}$ Department of orthopedics, Affiliated Hangzhou First People's Hospital, Zhejiang \\ University School of Medicine, No. 261 Huansha Road, Hangzhou, Zhejiang 310006, China
}

Huang et al:: ACE Combined with Electroacupuncture in the Treatment of Obese Patients with NAFLD

To investigate the clinical efficacy of acupoint catgut embedding combined with electroacupuncture in the treatment of obese patients with nonalcoholic fatty liver disease. A total of 102 obese patients with nonalcoholic fatty liver disease were randomly divided into control group $(n=51)$ and treatment group $(n=51)$. The patients in control group were given acupoint catgut embedding therapy, once every $2 \mathrm{w}$, for $3 \mathrm{mo}$; while the treatment group was given electroacupuncture therapy on the basis of the control group, once a $\mathrm{d}$ for $10 \mathrm{~min}$, for $3 \mathrm{mo}$. The biochemical parameters, body shape parameters, liver imaging indexes, clinical efficacy and adverse reactions of the two groups were observed before and after treatment. After treatment, the basic parameters (body weight, body mass index, waist circumference, body fat percentage), liver fat (controlled attenuation parameters, liver stiffness measurement), liver enzymes (alanine aminotransferase, aspartate aminotransferase), fasting (fasting insulin, fasting blood glucose) and blood lipids (high density lipoprotein, low density lipoprotein, triglyceride, total cholesterol) of the treatment group were significantly improved $(p<0.05)$; the body parameters (body weight, body mass index, waist circumference, body fat percentage), liver fat (controlled attenuation parameters, liver stiffness measurement), liver enzymes (alanine aminotransferase, aspartate aminotransferase), fasting (fasting insulin) and blood lipids (high density lipoprotein, low density lipoprotein, triglyceride, total cholesterol) of the control group were significantly improved $(\mathbf{p}<0.05)$ Lipid metabolism (high density lipoprotein, low density lipoprotein, triglyceride, total cholesterol) was significantly improved $(\mathbf{p}<0.05)$. The improvement of body weight, body mass index, waist circumference, controlled attenuation parameters and alanine aminotransferase in the treatment group was better than that in the control group $(p<0.05)$. Acupoint catgut embedding combined with electroacupuncture in the treatment of simple obesity complicated with fatty liver can improve the treatment effect of nonalcoholic fatty liver disease, correct the state of fatty liver and improve clinical symptoms, with more exact curative effect and more significant advantages, which is worthy of clinical promotion.

Key words: NAFLD, ACE, electroacupuncture, clinical efficacy

Nonalcoholic fatty liver disease (NAFLD), as a clinicopathological syndrome caused by excessive accumulation of fat in liver cells caused by nonalcoholic excessive intake and other identified liver injury factors, has the characteristics of insulin resistance (IR) and genetic susceptibility ${ }^{[1]}$. NAFLD covers a wide clinical range from nonalcoholic fatty liver (NAFL) to nonalcoholic steatohepatitis (NASH), pericellular fibrosis of NASH, progression to cirrhosis and finally liver failure and hepatocellular carcinoma $(\mathrm{HCC})^{[2]}$. With the development of urbanization and lifestyle changes in China, obesity and metabolic related diseases in the population are in a pandemic. The incidence rate of NAFLD has increased year by year, which has brought long-term health problems and economic burden to the masses and seriously affected the city's social and economic progress and development. Therefore, it is urgent to find a long term effective treatment to treat this kind of disease $\mathrm{e}^{[3,4]}$.

At present, a large number of studies have confirmed that electroacupuncture is effective in the treatment of

*Address for correspondence

E-mail: huangzhen780@163.com 
NAFLD with no side effects and green health, which has become the mainstream method for the treatment of NAFLD $^{[5-7]}$. Acupoint catgut embedding (ACE) therapy is a disease prevention and treatment method extended from the traditional acupuncture method. Its unique function of benign continuous stimulation of acupoints can well treat some chronic disease ${ }^{[8]}$. In the treatment of NAFLD, the first choice is lifestyle changes and exercise, through this long-term weight loss to achieve remission and cure of early NAFLD. Therefore, Catgut Embedding at acupoints, which can treat obesity, control body weight (BW), body fat percentage (FP) and reduce BMI, has attracted the attention of many scholars ${ }^{[9,10]}$. However, there are few studies on the clinical efficacy of the two methods in the treatment of NAFLD, so this study intends to use ACE combined with electroacupuncture in the treatment of NAFLD to explore its clinical effect.

\section{GENERAL CLINICAL DATA AND METHODS}

\section{General clinical data:}

A total of 102 patients with NASH in our hospital from September 2017 to September 2019 were randomly divided into control group (51 cases) and treatment group (51 cases). In the control group, there were 51 cases, 32 females and 19 males, aged from 21 to $55 \mathrm{y}$, with an average of $36.87 \pm 3.61 \mathrm{y}$; the course of disease was 2 to $15 \mathrm{y}$, with an average of $4.36 \pm 1.89 \mathrm{y}$. In the treatment group, there were 51 cases, 30 females and 21 males, with an average age of $35 \pm 4.37 \mathrm{y}$ (range, $22-54$ y) and a course of 3-14 y (range, $4.46 \pm 2.15 \mathrm{y}$ ). There was no significant difference in gender, age and course of disease between the two groups before treatment ( $\mathrm{p}>0.05)$.

\section{Diagnostic criteria:}

According to the guidelines for the prevention and treatment of nonalcoholic fatty liver disease (updated version in 2018) issued by the fatty liver and alcoholic liver disease group of Hepatology branch of Chinese Medical Association and the fatty liver disease expert committee of Chinese Medical Association ${ }^{[11]}$-No history of excessive drinking (male alcohol consumption $<30 \mathrm{~g} / \mathrm{d}$, female alcohol consumption $<20 \mathrm{~g} / \mathrm{d}$ ) and other specific causes of fatty liver disease (amiodarone, glucocorticoid) Hormone and other drugs, hepatitis $\mathrm{C}$ virus type 3 infection, autoimmune hepatitis, total parenteral nutrition and other specific diseases lead to fatty liver. Pathological significant liver steatosis and imaging diagnosis of fatty liver. According to the above two items, it can be diagnosed as nonalcoholic fatty liver disease.

Inclusive criteria-Those who meet the above diagnostic criteria; those who can persist in 4 courses of treatment; those who can complete the examination and complete the medical record. Exclusion criteria-Excluding alcoholic liver disease, viral hepatitis, drug induced liver disease, total parenteral nutrition, hepatolenticular degeneration and other specific diseases that can lead to fatty liver, as well as patients with other serious diseases at the onset stage; Patients who cannot complete the prescribed course of treatment; In pregnancy, lactation, mental illness and poor cooperation.

\section{Therapeutic methods:}

The control group was given catgut embedding therapy. Catgut embedding points-Zhongwan, huaroumen (bilateral), Daheng (bilateral), Guanyuan, Fenglong (bilateral), Ganshu (bilateral). Operation methodAsk the patient to lie on his back naturally, expose the catgut embedding part, locate the acupoint and disinfect the local routine. The disposable embedding needle was used. The Laser capture microdissection (LCM) long protein thread was put into the front end of the embedding needle with sterile forceps and the needle was held in the right hand. The embedding needle was inserted vertically into the acupoint and quickly penetrated to the required depth. After getting Qi, the needle tube was withdrawn and the needle core was pushed. The egg thread was embedded in the subcutaneous tissue or muscle layer of the acupoint. At the same time, the stone hand slowly withdrew from the needle tube and the cotton ball pressed the needle hole for a moment. The adhesive tape shall be the same. The covered tape can be removed after $24 \mathrm{~h}$. ACE was performed once every $2 \mathrm{w}$ for $3 \mathrm{mo}$.

Patients in the treatment group were treated with electroacupuncture on the basis of those in the control group. Acupoints Ganshu, Zusanli, Fenglong and Taichong were selected for electroacupuncture treatment. 0.5-inch filiform needle and g-6805 acupuncture therapeutic apparatus $(8-80 \mathrm{~Hz}, 14$ times/ $\min , 1.5 \mathrm{~V}, 1 \mathrm{~mA}$ and $10 \mathrm{~min}$ ) were used. The treatment lasted for $10 \mathrm{~min}$, once a d. After $6 \mathrm{~d}$ of continuous rest, the treatment lasted for 3 mo.

\section{Observation indexes:}

Biochemical indicators: Fasting blood samples were collected before and after treatment in both groups and the following biochemical indicators were detected: 
body liver enzymology, alanine aminotransferase (ALT), aspartate aminotransferase (AST), blood lipids, high density lipoprotein (HDL-C), low density lipoprotein (LDL-C), total cholesterol (TC), triglyceride (TG), fasting blood glucose (FPG), fasting insulin (FINS). The collection and detection were completed from the laboratory of our hospital.

Imaging indicators: The controlled attenuation parameters (CAP) and liver stiffness measurement (LSM) were obtained by the same experienced and blinded doctor in the same machine before and after treatment with Fibrotouch controlled attenuation parameter ultrasonic measurement method. CAP and LSM reference value ${ }^{[12]}$ : normal liver fat: $\mathrm{CAP}<238$ $\mathrm{db} / \mathrm{m}$, fat content $\leq 10 \%$; mild fatty liver: $238 \mathrm{db} / \mathrm{m}$ $\leq \mathrm{CAP}<259 \mathrm{db} / \mathrm{m}$, fat content in $11 \% \sim 33 \%$; moderate fatty liver: $259 \mathrm{db} / \mathrm{m} \leq \mathrm{CAP}<292 \mathrm{db} / \mathrm{m}$, fat content in $34 \% \sim 66 \%$; severe fatty liver: CAP $>292 \mathrm{db} / \mathrm{m}$, fat content $\geq 67 \%$; LSM reference range is $2.8 \sim 7.4 \mathrm{kpa}$, severe fatty liver and liver inflammatory reaction will lead to LSM rise.

Criteria for judging the efficacy of fatty liver: Complete recovery: ultrasound showed that the liver morphology returned to normal; markedly effective: ultrasound showed that the liver light spot was significantly improved and the rear echo was significantly reduced; effective: ultrasound showed that the fatty liver was slightly improved; ineffective: no change or even aggravation compared with before treatment, the total effective rate $=$ cure rate + significant efficiency+effective rate.

Body weight (BW), body mass index (BMI), waist circumference (WC) and body fat percentage (FP) of the two groups was measured according to "acupuncture treatment of obesity".
Omron HBF-306 body fat measuring instrument, the reference range was $12 \%-22 \%$ for male and $20 \%$ $-30 \%$ for female ${ }^{[10]}$.

The skin redness, swelling, pruritus, ulceration at the sutures, limb weakness, loss of appetite and abdominal pain were observed.

\section{Statistical analysis:}

SPSS 20.0 statistical software was used for data analysis. The measurement data were expressed as $\mathrm{x} \pm \mathrm{S}$ and the comparison of the rates was performed by $\chi^{2}$ test. The comparison of samples between groups and before and after treatment was performed by $\mathrm{t}$ test. *, ${ }^{\#} \mathrm{p}<0.05$ and $* *,{ }^{*} \mathrm{p}<0.01$ were considered statistically significant.

\section{RESULTS AND DISCUSSION}

Before treatment, there was no significant difference in BW, BMI, WC and FP between the two groups $(\mathrm{p}>0.05)$. After treatment, BW, BMI, WC and FP of NAFLD patients in the two groups were significantly decreased $(\mathrm{p}<0.05)$. After treatment, the improvement of BW, $\mathrm{BMI}$ and $\mathrm{WC}$ in the treatment group was significantly better than that in the control group $(\mathrm{p}<0.05)$ (Table 1).

As shown in Table 2, there was no significant difference in CAP and LSM between the two groups before treatment $(p>0.05)$. After treatment, CAP and LSM were significantly decreased in the two groups $(p<0.05)$. After treatment, the improvement of CAP in the treatment group was better than that in the control group $(\mathrm{p}<0.05)$.

ALT and AST were compared between the two groups before treatment $(p>0.05)$. Compared with before and after treatment, ALT and AST in two groups were

TABLE 1: COMPARISON OF BASIC PARAMETERS BETWEEN THE TWO GROUPS BEFORE AND AFTER TREATMENT

\begin{tabular}{|c|c|c|c|c|c|c|c|c|c|}
\hline \multirow[b]{2}{*}{ Group } & \multirow[b]{2}{*}{$\mathrm{n}$} & \multicolumn{2}{|c|}{ BW (kg) } & \multicolumn{2}{|c|}{ BMI } & \multicolumn{2}{|c|}{ WC (cm) } & \multicolumn{2}{|c|}{ FP (\%) } \\
\hline & & $\begin{array}{c}\text { Before } \\
\text { treatment }\end{array}$ & $\begin{array}{c}\text { After } \\
\text { treatment }\end{array}$ & $\begin{array}{c}\text { Before } \\
\text { treatment }\end{array}$ & $\begin{array}{c}\text { After } \\
\text { treatment }\end{array}$ & $\begin{array}{c}\text { Before } \\
\text { treatment }\end{array}$ & $\begin{array}{c}\text { After } \\
\text { treatment }\end{array}$ & $\begin{array}{c}\text { Before } \\
\text { treatment }\end{array}$ & $\begin{array}{c}\text { After } \\
\text { treatment }\end{array}$ \\
\hline & 51 & & $0.56 \pm 8.27$ & 25 & $26.09 \pm 2.24$ & & & & $\begin{array}{l}30.15 \pm \\
3.73^{*, \#}\end{array}$ \\
\hline Control & 51 & $82.15 \pm 11.22$ & $79.58 \pm 10.08$ & $29.11 \pm 2.17$ & $27.31 \pm 2.03$ & $97.57 \pm 7.45$ & $91.10 \pm 5.88$ & $33.86 \pm 6.52$ & $32.25 \pm 3.29$ \\
\hline
\end{tabular}

Note: Compared with before treatment: ${ }^{*} \mathrm{p}<0.05,{ }^{* *} \mathrm{p}<0.01$. Compared with the control group, ${ }^{\#} \mathrm{p}<0.05,{ }^{\#} \mathrm{p}<0.01$.

TABLE 2: COMPARISON OF LIVER FAT INDEX BETWEEN TWO GROUPS BEFORE AND AFTER TREATMENT

\begin{tabular}{lccccc}
\hline \multirow{2}{*}{ Group } & \multirow{2}{*}{$\mathrm{n}$} & \multicolumn{2}{c}{ CAP } & \multicolumn{2}{c}{ LSM } \\
\cline { 3 - 6 } & & Before treatment & After treatment & Before treatment & After treatment \\
\hline Treatment & 51 & $288.08 \pm 24.45$ & $267.15 \pm 28.49^{* *, \#}$ & $7.43 \pm 2.03$ & $6.11 \pm 1.54^{* *}$ \\
Control & 51 & $289.12 \pm 25.37$ & $276.23 \pm 30.33^{*}$ & $7.88 \pm 2.57$ & $6.89 \pm 1.78^{* *}$ \\
\hline
\end{tabular}

Note: Compared with before treatment, ${ }^{*} \mathrm{p}<0.05$, ${ }^{* *} \mathrm{p}<0.01$; Compared with the control group, ${ }^{*} \mathrm{p}<0.05$. 
significantly decreased $(p<0.05)$. After treatment, the improvement of ALT in the treatment group was better than that in the control group $(\mathrm{p}<0.05)$ (Table 3$)$.

There was no significant difference in fasting FPG and fins between the two groups before treatment $(p>0.05)$. After treatment, FPG and fins in the treatment group were significantly lower than those before treatment $(\mathrm{p}<0.05)$, as shown in Table 4 .

There was no significant difference in HDL-C, LDL-C, TG and TC between the two groups before treatment $(\mathrm{p}>0.05)$. After treatment, LDL-C, TG and TC in the treatment group were significantly lower than those before treatment $(\mathrm{p}<0.05)$ and HDL-C was significantly higher than that before treatment $(\mathrm{p}<0.05)$. In the control group, LDL-C and TG decreased significantly after treatment $(\mathrm{p}<0.05)$ and HDL-C increased significantly after treatment $(\mathrm{p}<0.05)$. As shown in Table 5.

As shown in Table 6, after the treatment, 7 cases were cured, 4 cases were markedly effective, 30 cases were effective and 10 cases were ineffective in the treatment group. The total number of cases in the treatment group was 51 and the total effective rate was $80.39 \%$. In the control group, 2 cases were cured, 4 cases were markedly effective, 29 cases were effective and 16 cases were ineffective. The total number of cases in the control group was 51 and the total effective rate was $68.63 \%$. The total effective rate of the treatment group was better than that of the control group $(\mathrm{p}<0.05)$.
As shown in Table 7, in the whole process of treatment, the adverse reactions in the treatment group: 2 cases of skin swelling or itching, 1 case of limb fatigue and 1 case of anorexia, the adverse reaction rate was $7.84 \%$; the adverse reactions in the control group: 3 cases of skin swelling or itching, 2 cases of abdominal pain, 4 cases of anorexia and 1 case of wound ulceration, the adverse reaction rate was $19.61 \%$. The difference was significant $(\mathrm{p}<0.05)$.

In recent years, with the development of society, great changes have taken place in people's life style, high oil and high sugar, high energy diet structure can be seen everywhere and physical activity is significantly reduced. These excess calories are stored in the body in the form of fat. When they reach a certain value and there is no other cause, they are called simple obesity. Studies have shown that obesity is closely related to environmental genetics, gender, race, nutritional status and marital relationship ${ }^{[13,14]}$. In China, the rising trend of nonalcoholic fatty liver disease and obesity is parallel, which has become one of the main factors of chronic liver injury and end-stage liver disease in China $^{[15]}$. Therefore, the treatment of simple obesity and nonalcoholic fatty liver disease ${ }^{[16,17]}$ has become a public health problem that cannot be ignored.

Electroacupuncture is to stimulate the filiform needle with pulse current on the basis of acupuncture, so as to enhance the curative effect and continuously stimulate the acupoints. To a certain extent, it can

TABLE 3: COMPARISON OF LIVER ENZYME INDEXES BETWEEN THE TWO GROUPS BEFORE AND AFTER TREATMENT

\begin{tabular}{lccccc}
\hline \multirow{2}{*}{ Group } & \multirow{2}{*}{$\mathrm{n}$} & \multicolumn{2}{c}{ ALT(U/L) } & \multicolumn{2}{c}{ AST(U/L) } \\
\cline { 3 - 6 } & & Before treatment & After treatment & Before treatment & After treatment \\
\hline Treatment & 51 & $36.67 \pm 16.91$ & $24.48 \pm 8.29^{* *}$ & $27.18 \pm 12.28$ & $20.78 \pm 4.68^{*}$ \\
Control & 51 & $38.87 \pm 17.58$ & $27.56 \pm 7.97^{*}$ & $28.71 \pm 13.09$ & $21.54 \pm 6.77^{*}$ \\
\hline
\end{tabular}

Note: Compared with before treatment, ${ }^{*} \mathrm{p}<0.05,{ }^{* *} \mathrm{p}<0.01$.

TABLE 4: COMPARISON OF THE CHANGES OF FASTING BLOOD GLUCOSE AND INSULIN BETWEEN THE TWO GROUPS BEFORE AND AFTER TREATMENT

\begin{tabular}{lccccc}
\hline \multirow{2}{*}{ Group } & \multirow{2}{*}{$\mathrm{n}$} & \multicolumn{2}{c}{ FPG $\left(\mathrm{mmol}^{\left.-\mathrm{L}^{-1}\right)}\right.$} & \multicolumn{2}{c}{ FINS(mU. $\left.\mathrm{L}^{-1}\right)$} \\
\cline { 3 - 6 } & & Before treatment & After treatment & Before treatment & After treatment \\
\hline Treatment & 51 & $5.76 \pm 0.71$ & $5.54 \pm 1.14^{*}$ & $19.09 \pm 9.17$ & $12.34 \pm 5.29^{* *}$ \\
Control & 51 & $5.87 \pm 0.65$ & $5.71 \pm 1.37$ & $19.93 \pm 9.08$ & $15.93 \pm 5.91^{*}$ \\
\hline
\end{tabular}

Note: Compared with before treatment, ${ }^{*} \mathrm{p}<0.05,{ }^{* *} \mathrm{p}<0.01$.

TABLE 5: COMPARISON OF BLOOD LIPID METABOLISM INDEXES BETWEEN THE TWO GROUPS BEFORE AND AFTER TREATMENT

\begin{tabular}{lccccccccc}
\hline & & \multicolumn{2}{c}{ HDL-C $(\mathrm{mmol} / \mathrm{L})$} & \multicolumn{2}{c}{ LDL-C $(\mathrm{mmol} / \mathrm{L})$} & \multicolumn{2}{c}{ TG $(\mathrm{mmol} / \mathrm{L})$} & \multicolumn{2}{c|}{ TC $(\mathrm{mmol} / \mathrm{L})$} \\
\cline { 2 - 9 } Group & $\mathrm{n}$ & $\begin{array}{c}\text { Before } \\
\text { treatment }\end{array}$ & $\begin{array}{c}\text { After } \\
\text { treatment }\end{array}$ & $\begin{array}{c}\text { Before } \\
\text { treatment }\end{array}$ & $\begin{array}{c}\text { After } \\
\text { treatment }\end{array}$ & $\begin{array}{c}\text { Before } \\
\text { treatment }\end{array}$ & $\begin{array}{c}\text { After } \\
\text { treatment }\end{array}$ & $\begin{array}{c}\text { Before } \\
\text { treatment }\end{array}$ & $\begin{array}{c}\text { After } \\
\text { treatment }\end{array}$ \\
\hline Treatment & 51 & $1.22 \pm 0.29$ & $1.39 \pm 0.38^{*}$ & $3.07 \pm 0.76$ & $2.73 \pm 0.54^{*}$ & $2.68 \pm 1.13$ & $1.73 \pm 0.39^{* *}$ & $5.52 \pm 0.74$ & $4.98 \pm 0.27^{* *}$ \\
Control & 51 & $1.19 \pm 0.33$ & $1.31 \pm 0.44^{*}$ & $3.01 \pm 0.78$ & $2.77 \pm 0.55^{*}$ & $2.74 \pm 1.38$ & $1.78 \pm 0.46^{* *}$ & $5.49 \pm 0.71$ & $5.39 \pm 0.33$ \\
\hline
\end{tabular}

Note: Compared with before treatment, ${ }^{*} p<0.05,{ }^{* *} p<0.01$. 
TABLE 6: COMPARISON OF CURATIVE EFFECT BETWEEN THE TWO GROUPS AFTER TREATMENT

\begin{tabular}{lcccccc}
\hline Group & $\mathbf{n}$ & Complete cure & Remarkable effect & Effective & Ineffective & Total effective rate \\
\hline Treatment & 51 & 7 & 4 & 30 & 10 & $41(80.39 \%)^{\#}$ \\
Control & 51 & 2 & 4 & 29 & 16 & $35(68.63 \%)$
\end{tabular}

Note: Compared with the control group, ${ }^{\sharp} \mathrm{p}<0.05$.

\section{TABLE 7: THE OCCURRENCE OF ADVERSE REACTION SYMPTOMS IN THE TWO GROUPS}

\begin{tabular}{lccccccc}
\hline Group & $\mathbf{n}$ & $\begin{array}{c}\text { Skin redness } \\
\text { or itching }\end{array}$ & $\begin{array}{c}\text { Limb } \\
\text { weakness }\end{array}$ & $\begin{array}{c}\text { Loss of } \\
\text { appetite }\end{array}$ & $\begin{array}{c}\text { The wound was } \\
\text { ulcerated by suture }\end{array}$ & $\begin{array}{c}\text { Abdominal } \\
\text { distension }\end{array}$ & $\begin{array}{c}\text { Adverse reaction } \\
\text { rate }\end{array}$ \\
\hline Treatment & 51 & 2 & 1 & 1 & 0 & 0 & $4(7.84 \%)^{\#}$ \\
Control & 51 & 3 & 0 & 4 & 1 & 2 & $10(19.61 \%)$ \\
\hline
\end{tabular}

Note: Compared with the control group, ${ }^{*} \mathrm{p}<0.05$.

replace the acupuncture technique. A large number of clinical and experimental studies have confirmed that electroacupuncture can effectively treat NAFLD. Catgut embedding at acupoints refers to the compound therapy of embedding absorbable catgut into acupoints to stimulate acupoints permanently. When the human body is active, the catgut entering the acupoints and the tissues move relatively, producing a lasting sense of acid swelling and continuously stimulating the acupoints ${ }^{[18]}$. Studies have shown that Catgut Embedding at acupoints can accelerate metabolism, promote fat decomposition, enhance human immunity and play a benign regulatory role in the body's neuroendocrine system ${ }^{[19-21]}$. Compared with electroacupuncture therapy, the impact on the body is more complex. At present, it is very rare to evaluate the clinical efficacy of the two methods in the treatment of NAFLD. Therefore, on this basis, we combined the two different methods in the treatment of NAFLD for clinical efficacy and impact on liver function. Japanese scholar Dai Tian Wenyan's research results show that Ganshu is often used in acupuncture for liver diseases ${ }^{[22]}$. Zusanli and Fenglong are acupoints of the stomach meridian of Foot Yangming. The stomach meridian of Foot Yangming is the meridian of multi Qi and multi blood. The acupoints of Zusanli and Fenglong are good at treating spleen and stomach diseases, Qi and blood, blood and other diseases. It has been proved that stimulation of Zusanli (ST36) can cause multi system reactions, especially the effects of digestive system and blood biochemistry. Taichong is the original point of the liver meridian, which has the effect of strengthening the body and eliminating pathogenic factors. It can be used for the deficiency and excess syndrome of the liver. The results showed that the curative effect of the treatment group was significantly better than that of the control group $(\mathrm{p}<0.05)$ After treatment, the body parameters (BW, BMI, WC, FP), liver fat (CAP, LSM), liver enzymes (ALT, AST), fasting (FINS, FPG) and blood lipids (HDL-C, LDL-C, TG, TC) of the treatment group were significantly improved $(p<0.05)$; the body parameters (BW, BMI, WC, FP), liver fat (CAP, LSM), liver enzymes of the control group were significantly improved $(\mathrm{p}<0.05)$ ALT, AST, fins and blood lipid metabolism (HDL-C, LDL-C, TG, TC) were significantly improved $(p<0.05)$. After treatment, the improvement of BW, BMI, WC, CAP and ALT in the treatment group was significantly better than that in the control group $(\mathrm{p}<0.05)$, that is, electroacupuncture can further improve the BW, BMI, WC, CAP and ALT of obese NAFLD patients on the basis of ACE therapy, indicating that electroacupuncture has good effects on reducing blood lipid, reducing intrahepatic lipid deposition, improving liver function and anti-liver fibrosis. The mechanism of action may be as follows: Acupuncture at Fenglong can transform both visible and invisible phlegm, regulate the spleen and stomach, promote transportation, eliminate phlegm turbidity and eliminate the source of phlegm; Zusanli can regulate the function of spleen and stomach. The experimental study found that after electroacupuncture at Zusanli, the hemorheological indexes of the patients were improved and the TC and TG were also decreased. Acupuncture at Fenglong could reduce the content of TC in serum. In addition, acupuncture and moxibustion can enhance the sympathetic nerve function, increase the levels of epinephrine and norepinephrine in the blood, activate the adenylate cyclase on the cell membrane, increase the cyclic adenosine monophosphate in the cell and produce the effect of lipolysis, so as to achieve the lipid-lowering effect. The improvement effect of CAP and ALT on ultrasound image characteristics is better, which may be that the stimulation of electroacupuncture therapy is more lasting and intense than catgut embedding therapy and the liquefaction and absorption process of catgut in the body will produce a series of biochemical reactions, so as to regulate the metabolic state.

In conclusion, $\mathrm{ACE}$ combined with electroacupuncture in the treatment of simple obesity complicated with fatty liver can improve the treatment effect of NAFLD, correct the state of fatty liver, improve the clinical 
symptoms, the curative effect is more exact and the advantages are more significant, which is worthy of clinical promotion.

\section{Acknowledgement:}

This work was supported by the Science and Technology Planning Project of Zhejiang Provincial Administration of Traditional Chinese Medicine (No. 2012ZB126).

\section{Conflicts of interest:}

The authors report no conflicts of interest.

\section{REFERENCES}

1. Chalasani N, Younossi Z, Lavine JE, Charlton M, Cusi $\mathrm{K}$, Rinella $\mathrm{M}$, et al. The diagnosis and management of nonalcoholic fatty liver disease: practice guidance from the American Association for the Study of Liver Diseases. Hepatology 2018;67:328-57.

2. Younossi ZM, Koenig AB, Abdelatif D, Fazel Y, Henry L, Wymer M. Global epidemiology of nonalcoholic fatty liver disease - meta-analytic assessment of prevalence, incidence and outcomes. Hepatology 2016;64:73-84.

3. Agha M, Agha R. The rising prevalence of obesity: part B-public health policy solutions. Int J Surg Oncol 2017;2:e19.

4. Arora SS, Axley P, Ahmed Z, Satapathy SK, Wong R, Kuo $\mathrm{YF}$, et al. Decreasing frequency and improved outcomes of hepatitis C-related liver transplantation in the era of directacting antivirals - a retrospective cohort study. Transpl Int 2019;32:854-64.

5. Cholankeril G, Gadiparthi C, Yoo ER, Dennis BB, Li AA, Hu $\mathrm{M}$, et al. Temporal trends associated with the rise in alcoholic liver disease-related liver transplantation in the United States. Transplantation 2019;103:131-9.

6. Du T, Yu X, Yuan G, Zhang J, Sun X. Combined influence of nonalcoholic fatty liver and body size phenotypes on diabetes risk. Cardiovasc Diabetol 2015;14:1-9.

7. Eguchi Y, Hyogo H, Ono M, Mizuta T, Ono N, Fujimoto $\mathrm{K}$, et al. Prevalence and associated metabolic factors of nonalcoholic fatty liver disease in the general population from 2009 to 2010 in Japan: a multicenter large retrospective study. J Gastroenterol 2012;47:586-95.

8. Nishioji K, Sumida Y, Kamaguchi M, Mochizuki N, Kobayashi M, Nishimura T, et al. Prevalence of and risk factors for non-alcoholic fatty liver disease in a non-obese Japanese population, 2011-2012. J Gastroenterol 2015;50:95-108.

9. Xu C, Yu C, Ma H, Xu L, Miao M, Li Y. Prevalence and risk factors for the development of nonalcoholic fatty liver disease in a nonobese Chinese population: the Zhejiang Zhenhai Study. Am J Gastroenterol 2013;108:1299-304.

10. Hao YP, Ma XJ, Luo YQ, Ni J, Dou JX, Hu YQ, et al. Serum vitamin $\mathrm{D}$ is associated with non-alcoholic fatty liver disease in Chinese males with normal weight and liver enzymes. Acta
Pharmacol Sin 2014;35:1150-6.

11. Liu P, Ma F, Lou H, Zhu Y, Chen Y. Relationship between normal serum uric acid levels and nonalcoholic fatty liver disease in postmenopausal women. Zhonghua Gan Zang Bing Za Zhi 2014;22:53-57.

12. Kim HJ, Kim HJ, Lee KE, Kim DJ, Kim SK, Ahn CW, et al. Metabolic significance of nonalcoholic fatty liver disease in nonobese, nondiabetic adults. Arch Intern Med 2004;164:216975.

13. Younes R, Bugianesi E. NASH in lean individuals. Semin Liver Dis 2019;39:86-95.

14. Wang AY, Dhaliwal J, Mouzaki M. Lean non-alcoholic fatty liver disease. Clin Nutr 2019;38:975-81.

15. Liu J, Xu C, Ying L, Zang S, Zhuang Z, Lv H, et al. Relationship of serum uric acid level with non-alcoholic fatty liver disease and its inflammation progression in non-obese adults. Hepatol Res 2017;47:E104-12.

16. Kleiner DE, Brunt EM, Van Natta M, Behling C, Contos MJ, Cummings OW, et al. Design and validation of a histological scoring system for nonalcoholic fatty liver disease. Hepatology 2005;41:1313-21.

17. Lu Z, Ma H, Xu C, Shao Z, Cen C, Li Y. Serum sialic acid level is significantly associated with nonalcoholic fatty liver disease in a nonobese Chinese population: a cross-sectional study. Biomed Res Int 2016;2016:5921589.

18. Luo ZX, Zeng Q, Luo R, Wang Y, Ge Q. Relative contributions of ectopic liver and abdominal fat accumulation to arterial stiffness. Endocr Pract 2015;21:574-80.

19. Qi JC, Huang JC, Lin QC, Zhao JM, Lin X, Chen LD, et al. Relationship between obstructive sleep apnea and nonalcoholic fatty liver disease in nonobese adults. Sleep Breath 2016;20:529-35.

20. Sun DQ, Wu SJ, Liu WY, Wang LR, Chen YR, Zhang DC, et al. Association of low-density lipoprotein cholesterol within the normal range and NAFLD in the non-obese Chinese population: a cross-sectional and longitudinal study. BMJ Open 2016;6:e013781.

21. Chen F, Esmaili S, Rogers GB, Bugianesi E, Petta S, Marchesini $\mathrm{G}$, et al. Lean NAFLD: a distinct entity shaped by differential metabolic adaptation. Hepatology 2020;71:1213-27.

22. Zhang S, Du T, Li M, Jia J, Lu H, Lin X, Yu X. Triglyceride glucose-body mass index is effective in identifying nonalcoholic fatty liver disease in nonobese subjects. Medicine 2017; 96:e7041.

This is an open access article distributed under the terms of the Creative Commons Attribution-NonCommercial-ShareAlike 3.0 License, which allows others to remix, tweak, and build upon the work non-commercially, as long as the author is credited and the new creations are licensed under the identical terms

This article was originally published in a special issue,
"Evolutionary Strategies in Biomedical Research and
Pharmaceutical Sciences" Indian J Pharm Sci 2020:83(3)
Spl issue;62-67

